Portland State University

PDXScholar

\title{
Effects of verbal and pantomime stimulus input on the short term sequential recall of aphasic adults
}

\author{
Lauryl S.I. Grotting \\ Portland State University
}

Follow this and additional works at: https://pdxscholar.library.pdx.edu/open_access_etds

Part of the Cognition and Perception Commons, and the Speech Pathology and Audiology Commons Let us know how access to this document benefits you.

\section{Recommended Citation}

Grotting, Lauryl S.I., "Effects of verbal and pantomime stimulus input on the short term sequential recall of aphasic adults" (1976). Dissertations and Theses. Paper 2266.

https://doi.org/10.15760/etd.2263

This Thesis is brought to you for free and open access. It has been accepted for inclusion in Dissertations and Theses by an authorized administrator of PDXScholar. Please contact us if we can make this document more accessible: pdxscholar@pdx.edu. 
AN ABSTRACT OF THE THESIS OF Lauryl S. I. Grotting for the Master of Science in Speech Communication with emphasis in Speech and Hearing Sciences presented February 19, 1976.

Title: Effects of Verbal and Pantomime Stimulus Input on the Short Term Sequential Recall of Aphasic Adults.

APPROVED BY MEMBERS OF THE THESIS COMMITTEE:

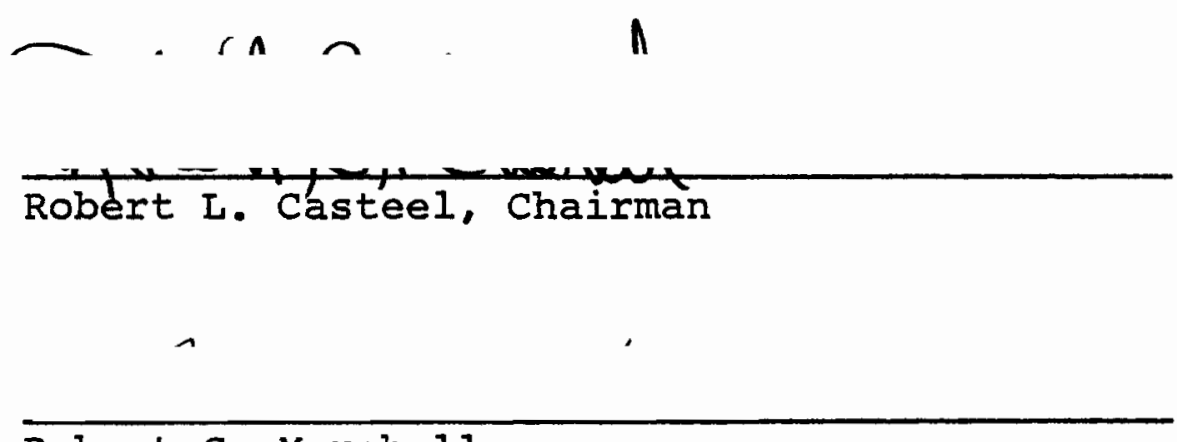

Robert C. Marshall

Máry E. Goydon

Ronald E. Smith

The question posed in this investigation was: Which stimulus input mode, verbal, pantomime, or combined verbal and pantomime, is more effective in facilitating short term 
sequential recall of language material with aphasic adults? To answer this question, thirty-six aphasic subjects were randomly divided into three groups of twelve subjects per group, six with high overall scores on the Porch Index of Communicative Ability (PICA) and six with low overall scores. Each subject in the three groups performed a total of thirty recall tasks which included ten tasks of one, two, and three items respectively. The experimental task presented to the first group consisted of thirty verbal sequences of words. The second group was given thirty simple pantomime sequences, and the third group's task consisted of thirty combined verbal and simple pantomime sequences.

A mixed design Three Factor Analysis of Variance ( $2 \mathrm{x}$ $3 \times 3)$ was utilized to statistically determine the main effects and interactions of 1) the input modality used in presentation of stimuli (verbal, simple pantomime, or combined), 2) the high or low overall PICA scores for subjects, and 3) the sequence length of the recall task (one, two or three items), on aphasic subject's sequential recall performance.

All interactions between variables were determined to be nonsignificant, thereby making it possible to look directly at the main effects. Subjects with high and low 
PICA scores did obtain significantly different performance scores, with the low PICA subject groups scoring proportionately lower than the high PICA groups on all sequential tasks. The present study, therefore, supported Pickett's data (1972) which showed that aphasic's ability to use verbal and gestural information was related to overall severity of aphasia as reflected by overall PICA scores.

Results also indicated that as sequence length increased from one to three stimuli, aphasics' performance decreased significantly. These findings also support earlier work of Brown (1973), Luria (1966, 1967), and Schuell, et al. (1965), and their contention that sequence length adversely affects the performance of aphasics.

Neither the verbal, pantomime, nor combined input modes used in the presentation of stimuli, had a significantly different effect on aphasic subject's sequential recall performance. Therefore, the primary question posed in this investigation can be answered: There does not appear to be a significantly different effect between the verbal, pantomime and combined input modes, when they are used for instructing aphasic subjects in a sequential recall task. These findings would seem to support the theory that a central processing system for language material exists 
which becomes impaired across all modalities in persons with aphasia. 


\section{EFFECTS OF VERBAL AND PANTOMIME STIMULUS \\ INPUT ON THE SHORT TERM SEQUENTIAL \\ RECALL OF APHASIC ADULTS}

\section{by}

IAURYL SUZANNE IVERS GROTTING

A thesis submitted in partial fulfillment of the requirements for the degree of

\section{MASTER OF SCIENCE}

in

SPEECH COMMUNICATION WITH EMPHASIS IN

SPEECH PATHOLOGY/AUDIOLOGY

Portland State University

1976 
TO THE OFFICE OF GRADUATE STUDIES AND RESEARCH:

The members of the Committee approve the thesis of

Lauryl Suzanne Ivers Grotting presented February 19, 1976.

Robert I. Casteel, Chairman

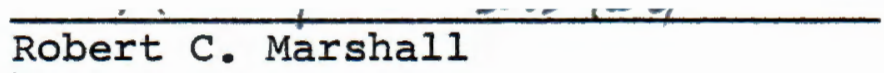

Mary E. Gordon

Ronald E. Smith

APPROVED:

Robeft Vogelsang, Head, Department of Speech Communication

Richard B. Halley, Acting/Dean of Graduate Studies and Research 


\section{ACKNOWLEDGEMENTS}

(AWARDS)

BEST ACTOR: Awards go to Dr. Robert Casteel and Dr. Robert Marsha11. I am indebted to Portland State University and to the Portland Veterans Administration Hospital, and to these two men whose support, expertise, and friendship I value most highly.

TECHNICAL DIRECTOR: The award goes to Ms. Mary Gordon for superb work and devotion of time to assist me in achieving form and clarity in this thesis. Also awarded is Dr. Ronald Smith for his insight and contribution. SCORE: The results indicate the score adds up to an award for Dr. Dan Gray, for his statistical wisdom and philosophy, and for devoting so much of his time communicating it to me.

BEST SUPPORTING ACTOR: FOr support and understanding beyond the call of matrimony, the award goes to my best friend and husband, John Grotting.

BEST SUPPORTING ACTRESS: The award is presented to Yvonne Deligiorgis for devoting her time and talent to typing this entire thesis, twice!

Thank you. 
TABLE OF CONTENTS

PAGE

ACKNOWLEDGEMENTS . . . . . . . . . . . . . LIST OF TABLES . . . . . . . . . . . . . vi vi LIST OF FIGURES . . . . . . . . . . . . . v vii CHAPTER

I INTRODUCTION ............. . 1

Statement of Purpose . . . . . . 3

Definitions .......... 3

II REVIEW OF THE LITERATURE . . . . . . . 5

Gestural Abilities of Aphasics . . . 5

Significance of Gestural Ability in

Modality Recovery ........ . 8

Short Term Retention ........ 9

Short Term Storage......... 10

III METHODS ............... 13

Subjects . . . . . . . . . . 13

Procedure ............ . 14

Scoring . . . . . . . . . . 19

Data Analysis . . . . . . . 20 
IV RESULTS AND DISCUSSION . . . . . . . . . $2 I$

Results . . . . . . . . . . . 21

Discussion . . . . . . . . . . 27

$\mathrm{V}$ CONCLUSIONS AND IMPLICATIONS . . . . . . . 36

Summary and Conclusions . . . . . 36

Clinical Implications . . . . . . 38

Implications for Further Research . . 39

SOURCES OF REFERENCE . . . . . . . . . . . . . . . 41

APPENDIX A . . . . . . . . . . . . . . . . 44

Subject Information

APPENDIX B . . . . . . . . . . . . . . . . . 46

High PICA Subject's Raw Scores

Low PICA Subject's Raw Scores 


\section{LIST OF TABLES}

TABLE

PAGE

I Division of Groups . . . . . . . . . . 14

II Sequential Presentation of Items . . . . . 16

II Analysis of Three Input Variables: High-

Low PICA, Input Modality, Sequence

Length . . . . . . . . . . . . 23

IV Subject's PICA Scores . . . . . . . . 28

$\mathrm{V}$ Analysis of Variance of Subjects and Sub-

ject Groups . . . . . . . . . 28 


\section{IIST OF FIGURES}

FIGURE

PAGE

1 Group Means for Subjects with High PICA

Overall Scores $(N=18)$ and Subjects

with Low PICA Scores $(N=18)$, for

Three Sequence Lengths . . . . . . . 24

2 Group Means for Subjects with High PICA

Overall Scores $(N=6)$ and Subjects with

Low PICA Overall Scores $(N=6)$ for the

Three Stimulus Input Modality Groups . . 24

3 Group Means for Subjects with High PICA

Overall Scores in Each of Three Stimulus

Input Modality Groups (Verbal, Pantomime,

Combined; $\mathrm{N}=6$ ), and Group Means for

Subjects with Low PICA Scores in Each

of the Three Stimulus Input Modality

Groups $(N=6)$, for Three Sequence Lengths. 25

4 Multi-Dimensional Scoring Pattern for the

High PICA Input Modality Groups $(\mathrm{N}=6)$ - . 33

5 Multi-Dimensional Scoring Pattern for the

Low PICA Input Modality Groups $(\mathrm{N}=6)$ - . 33 
CHAPTER I

\section{INTRODUCTION}

Language is a symbolic process. It incorporates both verbal and non-verbal symbols. The term aphasia implies an impairment in the ability to process and formulate language symbols in all modalities (Schuell, et al. 1965). The research in aphasia has dealt primarily with verbal language and has revealed valuable information. Considering the use of non-verbal language by non-aphasic individuals, it seems logical this communication mode should also be explored and its potential importance made known.

Recent research has been undertaken to determine the relationship between gestural and verbal language in aphasic persons (Duffy, et al. 1975; Fordyce and Jones, 1966; Goodglass and Kaplan, 1963; Pickett, 1972). While Goodglass and Kaplan's research (1963) indicates that expressive gestural ability is not related to overall severity of aphasia or verbal language abilities, contradictory evidence has been offered by other researchers. Duffy, et al. (1975) and Pickett (1972), for example, experimented with both 
receptive and expressive abilities of aphasics and concluded verbal and gestural language modes are positively interrelated and representative of a central symbol ability which becomes impaired with aphasia. Fordyce and Jones' (1966) research on the efficacy of oral and pantomime instructions suggests that left hemisphere cerebrovascular accident (CVA) patients perform better with pantomime than verbal instruction. Clearly, more research is needed to determine the nature of the functional relationship between different modes of language in the aphasic population. No attempts, to date, have been made to investigate the possible relationships between verbal and non-verbal language symbols in short term sequential recall, or the possible facilitating effect of combining these methods of communication. Results showing non-verbal receptive language to be impaired to the same degree as verbal receptive skills may be further evidence for a central language deficit. However, if either the verbal or non-verbal language input modality is used more efficiently than the other modality in a series of tasks, separate modality capacities may be indicated, which may be affected to different degrees in a language processing system. It would also be of interest to note whether the combined input modes (verbal and 
pantomime) have a facilitating effect on aphasics' processing. Finally, if it were shown that non-verbal language, such as simple pantomime, facilitated recall with aphasic persons, then this type of language might be considered for use in the treatment setting.

\section{PURPOSE OF THE INVESTIGATION}

This study was designed to compare the effects of three methods of stimulus input on the aphasic adult's short term sequential recall ability. This includes instructions by means of 1) a verbal stimulus alone; 2) a simple pantomime stimulus alone; and 3) a combined verbal and simple pantomime stimulus.

The primary question posed in this investigation was: Which stimulus mode, verbal, pantomime or combined verbal and pantomime, is more effective in the short term sequential recall of language material with aphasic adults?

\section{DEFINITIONS}

The following definitions are provided in order to clarify some of the terminology used in this text.

Aphasia: is a deficit in the ability to process and formulate language symbols in all modalities, in persons who have sustained localized cerebral damage (Brookshire, 1973; Eisenson, 1973; Schuell, 
et al. 1965).

Gesture: is a single unit of body movement which may serve as a sign carrying some meaning; it is more likely to accompany speech than pantomime (Duffy, et al. 1975; Ekman, 1972; Pickett, 1972).

Inner Speech: is a process of mental recoding of input stimuli into verbal language symbols (Goodglass, et al. 1974).

Lanquage: is the general system of encoding and decoding of arbitrary symbols in which a basic competency can be shown for carrying out certain functions, e.g., interrogatives, truth-functional judgements, etc. (Premack, 1975).

Non-Verbal Language: is a component of language differing from verbal language only in mode of expression. This would include emblems, signs, gestures, gesticulation, pantomime, and written forms of language (Duffy, et al. 1975; Ekman, 1972; Goodglass and Kaplan, 1963; Sarno, 1972; Pickett, 1972).

Short Term Recall: is a cognitive task that involves a single presentation of a small amount of material followed within seconds by a recall test (Baddeley, 1972). Where verbal material is used, the retention and recall of materials may be termed verbal retention and verbal recall.

Simple Pantomime: is a more improvised condition than gesture in which a person deliberately uses a simple sequential body movement to convey a message in the absence of speech (Duffy, et al. 1975; Goodglass and Kaplan, 1963; Pickett, 1972).

Verbal Language: is oral communication produced by a complex process which includes sensorimotor coordinations (Luria, 1966). 
CHAPTER II

\section{REVIEW OF THE LITERATURE}

\section{GESTURAL ABILITIES OF APHASICS}

Many of today's aphasiologists refer to gesture and pantomime as language modes (Critchley, 1970; Duffy, et a1.,1975; Fordyce and Jones, 1966; Pick, 1973; Pickett, 1972). Investigations of the verbal and gestural abilities of aphasic persons (Duffy, et al..1975; Fordyce and Jones, 1966; Goodglass and Kaplan, 1963; Pickett, 1972) have concerned themselves with whether or not gestural and verbal modes of language are 1) functioning as different language systems, 2) parts of the same central language processing system, and 3) systems which are impaired to the same extent in aphasia. Research has also been conducted to determine the advantage of using gestures or signs as a substitute or compensatory form of communication for patients incapable of communicating verbally (Eagleson, et al.,1967; Sarsno, et al.,1972; Skelly, et al.,1974).

In answering the above three-part question, Good- 
glass and Kaplan (1963) and Pickett (1972) examined the expressive abilities of aphasic persons. Goodglass and Kaplan (1963) used verbal instructions in a task designed to evaluate aphasic's use of gestures and simple pantomime in a variety of expressive and imitative tasks. They did not find a clear correlation of severity of aphasia with gestural deficiency, or an ability of the aphasics to profit from imitation. They, therefore, concluded gestural deficiency is best understood as an ideokinetic apraxic disorder, not a central language processing disorder. Pickett (1972) investigated both expressive and receptive abilities of aphasics. He designed eight tasks to assess tactile recognition, pantomimic expression, gestural recognition and imitative ability of aphasic patients. He found that gestural ability was related to the overall severity of aphasia, and that subjects were able to improve their gestural performance with imitation. His results were inconsistent with those of Goodglass and Kaplan (1963) and supported a central language processing theory of gestural deficit. The results also showed gestural ability to be impaired with aphasia. Another important contribution from Pickett's study was the finding that gestural ability could be measured by either expressive or receptive per- 
formance. He found a positive correlation of .70 between expressive and receptive scores on the gestural tests. Duffy, et al. (1975) and Fordyce and Jones (1966) investigated the gestural receptive abilities of aphasics. Duffy, et al. (1975) administered pantomime recognition and verbal recognition tests to aphasic subjects in order to determine the relationship between these two abilities. His findings were consistent with Pickett's (1972) and indicated receptive pantomime ability becomes impaired with aphasia and is highly correlated with verbal abilities. Duffy, et al. (1975) concluded that "there is a common symbolic competence underlying gestural and verbal communication" which becomes impaired with aphasia.

Duffy, et al. (1975) found that the relationship between gestural and verbal modes was constant in both normal and aphasic subjects, with verbal recognition somewhat better than pantomime recognition ability. Penny (1975), in a review of the literature on normal subjects in recall tasks, also noted higher verbal than visual recognition abilities. Alajouanine and Lhermitte (1964), Fordyce and Jones (1966), and Sarno, et al. (1972) provided evidence opposite from Duffy and Penny: gestures and pantomime may actually be used more effectively than verbal language with 
aphasic adults.

The Fordyce and Jones' (1966) experiment involved the use of oral and pantomimed instructions given to brain damaged patients. They found left hemisphere damaged patients scored significantly higher when instructed by pantomime than when instructed orally for the same task.

\section{SIGNIFICANCE OF GESTURAI ABILITY}

IN MODALITY RECOVERY

Luria's work (1966) suggests one mode of language may be affected more than another depending upon the type of aphasia and location of brain damage. Where this modality difference occurs, there may be some compensation of one mode for another.

Skelly, et al. (1974) investigated the possible compensation and facilitation effects of using the Amerind Indian Sign System on spontaneous oral speech and gestural ability of severe apraxics. The Amerind Indian Sign System is a telegraphic communication procedure using commonly understood gestures and signs to convey a message. The sign system was modified for apraxics to be a one-hand dialect. Skelly found the apraxic's improvement in gestural ability was very slight, but she did note improvement in oral verbalization. She cautioned that more research is 
necessary.

Buck (1968) and Pick (1973) indicated that aphasics may regress to more primitive modes of verbal or non-verbal language. Pick felt this was evidenced by the aphasic person's use and ease in understanding gestures.

\section{SHORT TERM RETENTION}

Although there exists an abundance of literature on memory, there seems to be considerable controversy about its specific attributes. Penny (1975) provided an excellent review of the literature in short term memory. Of interest to the present study was her find that auditory retention was generally regarded as superior to visual retention, and in normals immediate visual retention is approximately five to seven words (Penny, 1975). Penny's findings were consistent with the earlier research of Miller (1956a, 1956b) and sperling (1963).

The retention abilities of aphasics have been found to be reduced relative to normals (Buck, 1968; Luria, 1966; Schuell, et al.,1965; Swinney and Taylor, 1971). Schuell, et al. (1965) and Luria (1966) noted that aphasic persons demonstrated difficulty in visually or auditorily retaining more than three to four words. In auditory retention, Iuria 
(1966) observed that aphasics retained only the most recent words (retroactive inhibition or recency effect). This recency effect was not found in visual presentations. Luria also noted that a visually presented series of items was retained better than an oral presentation with aphasic patients.

The time limits or response latency, on short term retention tasks, are rather arbitrary. Baddeley (1972) and Sperling (1963) stated that after delays of ten to thirty seconds, short term memory was no longer being studied in normals. Wickelgren (1965) viewed short term memory as that retention assessed after less than twenty seconds, when material was presented at a rate of less than two seconds per item. Filby, et al. (1963) found that response latency was a factor in the discrimination behavior of aphasics in that more time was needed on longer words. To date, however, there have been no studies to adequately assess the latency time of aphasics in a sequential recall tasks, or to determine what limits there are on short term retention in this group.

IV. SHORT TERM STORAGE

Penny (1975) and Sperling (1963) theorized there were 
separate short term stores or feedback loops in the brain for auditory and visual information. Sperling (1963) suggested more time should be given when presenting visual recognition material to equate it with verbal material. He also speculated that only one input is rehearsable at any one time and a short amount of time is required to switch from one input modality to another; therefore, when auditory and visual modes are combined, recognition may be slower.

The manner in which material is stored in the brain is also not well understood. In her review of the literature, Penny (1975) found that many writers refer to verbal coding of visual as well as auditory information; however, studies which directly measured visual retention in short term memory did not support the hypothesis of verbal coding (Penny, 1975; Sternberg, 1966). Goodglass, et al. (1974) studied "inner speech" or verbal coding in aphasics and found no evidence of verbal coding of visual objects in this group. They did, however, find evidence for this in their non-aphasic controls.

Apparently, further research is needed in all areas of the aphasic's gestural language abilities. While most writers appear to agree there is a general deficit in 
gestural ability with aphasia, controversy remains in understanding to what it is attributable, and in understanding how this modality relates to the auditory-verbal language modality.

So little has been done to investigate short term memory in aphasics that only very arbitrary time limits and storage speculations can be made at this point. 
CHAPTER III

METHODS

I. SUBJECTS

Thirty-six aphasic adults, three groups of twelve subjects each (see Table I) were selected for this investigation. All subjects met the following criteria (See Appendix A): 1. Subjects had suffered a single major thromboembolic cerebrovascular accident.

2. Subjects were at least three months post-onset $\left(\mathrm{P} . \mathrm{O}^{\prime}\right)$

3. Porch Index of Communicative Ability (PICA) (1967) scores were located between the twentieth and ninety-eighth overall percentile rankings (a wide range of severity, with higher scores reflecting better language abilities), and the profiles were consistent with the language diagnosis of aphasia made by a certified speech pathologist.

4. At the time of the $\underline{P I C A}$ testing, vision and hearing were judged by the examiner to be adequate for responding. 
The thirty-six subjects were randomly divided into three groups with the exception that six subjects designated as having high overall PICA scores (above 65th percentile) and six subjects having low PICA scores (65th percentile and below) were assigned to each group. Appendix B shows that the thirty-six subjects were divided into three input modality groups (Verbal, Pantomime, or Combined) and then subdivided into high and low PICA groups for a total of six groups, six subjects per group: High PICA-Verbal; High PICA-Pantomime; High PICA-Combined; Low PICA-Verbal; LOW PICA-Pantomime; Low PICA-Combined.

TABLE I

DIVISION OF GROUPS

\begin{tabular}{|c|c|l|}
\hline & & \\
\hline Group Number & Subjects in Group & $\begin{array}{l}\text { Communication } \\
\text { Stimulus Used in } \\
\text { Task Sequence }\end{array}$ \\
\hline 1 & 12 & $\begin{array}{l}\text { Verbal Stimulus } \\
\text { Alone } \\
\text { Simple Pantomime } \\
\text { Stimulus Alone } \\
\text { Verbal and Simple } \\
\text { Pantomime Stim- } \\
\text { ulus Combined }\end{array}$ \\
\hline
\end{tabular}

II. PROCEDURE

Each subject performed a total of thirty tasks which 
included ten tasks at each of three sequence lengths: one, two or three items per sequence.

Eight real objects were used in the sequential tasks and were placed at equal distances from each other on a table directly in front of the subject. The names for all eight items were monosyllabic words:

ball
comb
cup
key
match
pen
ring
spoon

Sequence, order of the tasks and their presentation length (one, two, or three items) were originally determined by use of a random order table and then individually balanced, to assure equal distribution and representation of items (See Table II).

The items were presented one row at a time, in the same sequential order to all groups.

During administration of the tasks, the subject and examiner sat across from one another at a large table in a quiet room.

The experimental task set presented to Group 1 was in the form of thirty verbal sequences. The experimental tasks were administered individually to each subject and 
testing was completed in one session. All items used in the task set were verbally named for the subject during a brief training period prior to testing. Two sample sequences of two items each were used in training. Demonstrations were provided if needed. Subjects who were unable to show they understood how to respond to the training tasks were excluded from the study.

\section{TABLE II}

SEQUENTIAL PRESENTATION OF ITEMS

\begin{tabular}{|l|l|l|l|}
\hline Row & Sequences & \multicolumn{2}{|l|}{} \\
\hline 1 & key, match & cup & ball, ring, key \\
2 & ring, spoon, cup & match, ball & comb \\
3 & pen, key, ring & match & cup, pen \\
4 & ball & $\begin{array}{l}\text { comb } \\
\text { cup, pen, ring }\end{array}$ & spoon \\
5 & ring, comb & kall, pen \\
6 & cup & pen, ring, spoon \\
7 & match, key & ball, match, cup & spoon, comb, key \\
8 & comb, spoon & comb \\
9 & match, cup, ball & spoon, cup & comb, ball, pen \\
10 & key &
\end{tabular}


When the subject appeared comfortable with the task and relaxed, testing began. Subjects were verbally and gesturally instructed to point to the appropriate items in front of them indicating the correct sequence after each task presentation. Instructions for Group 1 were as follows:

Look at me and listen to me carefully. I will say the names of some of these objects. You will point only to the ones I said, in exactly the same order. It's important that you point in the same order. Ready (cue with "ready" or eye contact before each task).

A single head nod by the examiner cued the subject to begin immediately after the sequence was presented. Seven social reinforcers ("good") were given at fixed intervals during testing. Presentation of verbal stimuli did not exceed one second per item with one second intervals between items. Each task was timed and a perfect score meant correct sequential recall within a twenty second time limit. By twenty seconds, the subject's score was recorded. If no response was made in twenty seconds, the score was recorded, 0 , and a transition was made to the next task following the examiner's comment: "Let's go on to the next one." Where a response was made in less than twenty seconds, the examiner proceeded immediately to the next task. All tasks were presented to subjects in the same order of presenta- 
tion: one row at a time. Timing was tracked by the use of the second hand on a clock or watch. During administration of the tasks, the subject and examiner sat across from one another at a large table in a quiet room.

The tasks presented to each subject in Group 2 were the same as Group 1, differing only in the mode of presentation. The tasks for Group 2 were presented in simple pantomime instead of verbal language. All items were gesturally and verbally named for the subject during a brief training period prior to testing. Two sample sequences of two items each were used in training. Demonstrations were provided if needed. Subjects who were unable to show they understood how to respond to the training task were excluded from the study.

Testing for Group 2 followed the same procedure as Group 1. The instructions varied slightly.

Look at me and watch me carefully. I will show you the hand signals for some of these objects. You will point only to the ones I showed, in exactly the same order. It's important that you point in the same order. Ready (cue with "ready" or eye contact before each task).

Presentation of simple pantomime stimulus did not exceed one second per item with one second intervals between items.

Subjects in Group 3 received the same procedures in 
training and testing as Groups 1 and 2. However, instead of receiving the tasks in only one language mode, their tasks were presented in combined verbal-simple pantomime sequences. Verbal and simple pantomime stimuli were presented simultaneously. All items were gesturally and verbally named for the subject during a brief training period prior to testing.

Instructions for Group 3 were as follows:

Look at me. Watch and listen carefully. I will say the names of some of these objects and show you the hand signals. You will point only to the ones I said and showed in exactly the same order. It's important that you point in the same order. Ready (cue with "ready" or eye contact before each task).

\section{SCORING}

In the scoring of responses, the following system was used:

4 - Correct or Self Correction - an accurate identification of all items in sequence within the time limit of twenty seconds.

3 - Out of Sequence - a selection of all appropriate items, within the time limit but out of sequence.

2 - Incomplete - an accurate selection of the first one or two items in the sequence, but not the total sequence.

1 - Incomplete - an accurate selection of the last one or two items in the sequence, but not the total sequence. 
0 - No Response or Incorrect Pointing or Repetition - within a twenty second time limit.

IV. DATA ANALYSIS

For statistical analysis, a mixed design Three Factor Analysis of Variance ( $2 \times 3 \times 3)$ was utilized (Winer, 1962). 


\section{RESULTS AND DISCUSSION}

\section{I . RESULTS}

Each of the thirty-six subjects in this investigation made thirty pointing responses to the recall task, ten at each of three sequence lengths. A response was scored on a 0-4 point scale, the highest possible score being 120 points, or 40 points for each of the three sequence lengths. Appendix B contains the total individual scores of subjects for each of the three sequence lengths. Appendix B shows that the thirty-six subjects were divided into three input modality groups (Verbal, Pantomime or Combined) and then subdivided into high and low PICA groups for a total of six groups, six subjects per group: High PICA-Verbal; High PICAPantomime; High PICA-Combined; Low PICA-Verbal; Low PICAPantomime; Low PICA-Combined. The raw scores for all six groups were converted into percentage scores and from these, group mean percentage scores were obtained. The group mean percentages were submitted to a 2 × 3 x 3 mixed design 
Three Factor Analysis of Variance (Winer, 1962). The ana1ysis considered the main effects and interactions between 1) high versus low PICA score, 2) sequence length, and 3) mode of presentation.

Table III contains the summary of the analysis of variance and indicates all interactions between the three variables were nonsignificant (p>.01). Figures 1,2 and 3 graphically illustrate the interactions between sequence length and PICA score $(F=2.34 ; d f=2,60)$, stimulus input mode and PICA score $(F=.041 ; d f=2,30)$, and mode of presentation and sequence length $(F=.146 ; d f=4,60)$, respectively. Because there were no significant interactions between variables, the main effects (input mode, high-low PICA score, sequence length) were analyzed separately. The primary purpose of this investigation was to determine whether or not aphasics utilized one input modality more effectively than others in a sequential recall task. The input modalities studied were auditory-verbal, visualpantomime, and combined verbal-pantomime. Figure 3 illustrates there was no significant difference $(F=.035 ; d f=2,30)$ between the three input modalities and their effects on the aphasic's group mean percentage scores, thus supporting the notion of Schuell, et al. (1965) that aphasic persons are 
TABLE III

ANALYSIS OF VARIANCE OF THREE VARIABLES:

HIGH-LOW PICA, INPUT MODALITY,

SEQUENCE LENGTH

\begin{tabular}{|c|c|c|c|c|c|}
\hline Source & $\mathrm{df}$ & Sums of Squares & Mean Square & $\underline{F}$ & $\underline{P}$ \\
\hline $\begin{array}{l}\text { Within Subjects } \\
\text { Sequence Length } \\
\text { PICA x Sequence Length } \\
\text { Input Mode } \times \text { Seq Length } \\
\text { PICA x Input Mode } x \text { Seq } \\
\text { Length } \\
\text { Subjects within Groups }\end{array}$ & $\begin{array}{r}72 \\
2 \\
2 \\
4 \\
4 \\
60\end{array}$ & $\begin{array}{r}15291.666 \\
8336.226 \\
489.699 \\
138.425 \\
\\
61.342 \\
6265.972\end{array}$ & $\begin{array}{r}4168.113 \\
244.849 \\
34.606 \\
15.335 \\
104.432\end{array}$ & $\begin{array}{r}39.991 \\
2.344 \\
.331 \\
.146 \\
----\end{array}$ & $\begin{array}{r}<.001 \\
>.1 \\
\text { NS } \\
\text { NS } \\
----\end{array}$ \\
\hline TOTAL & 107 & 36115.913 & & & \\
\hline
\end{tabular}




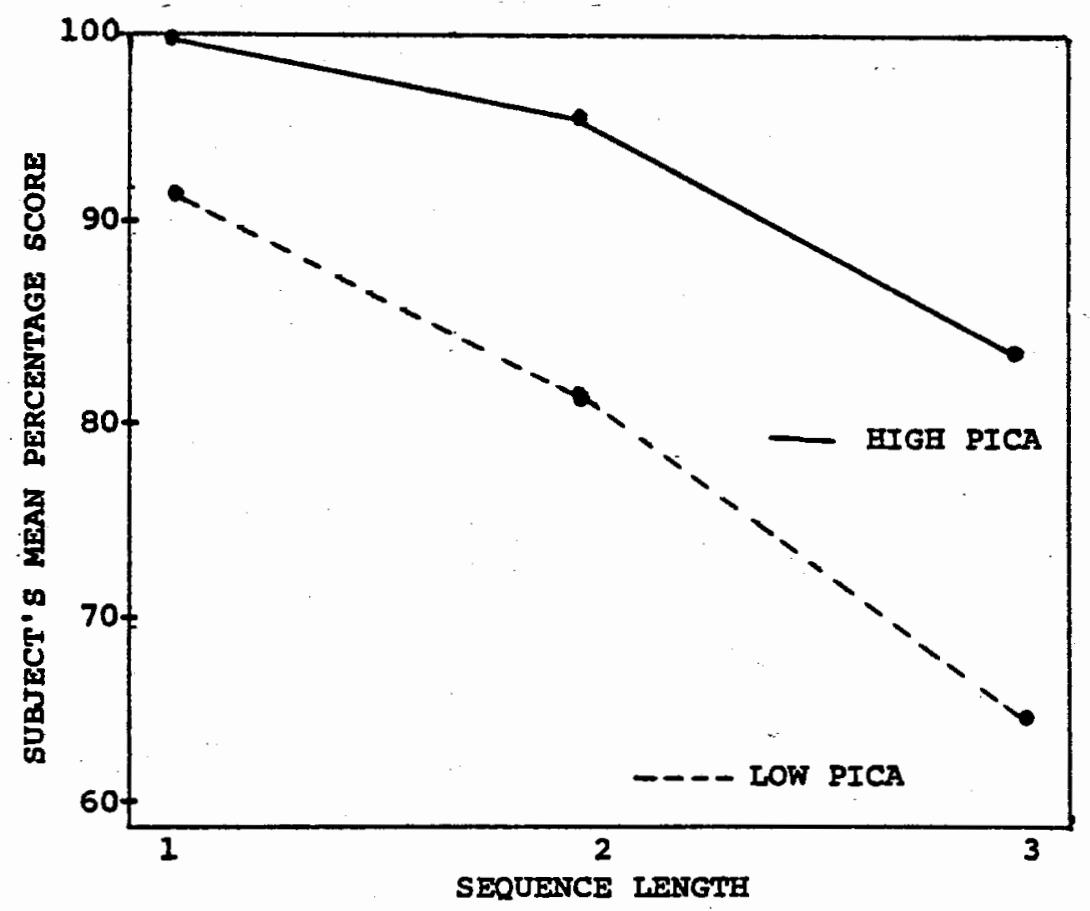

Fiqure 1. Group means for subjects with high PICA overall scores $(N=18)$ and subjects with low PICA scores $(N=18)$, for three sequence lengths.

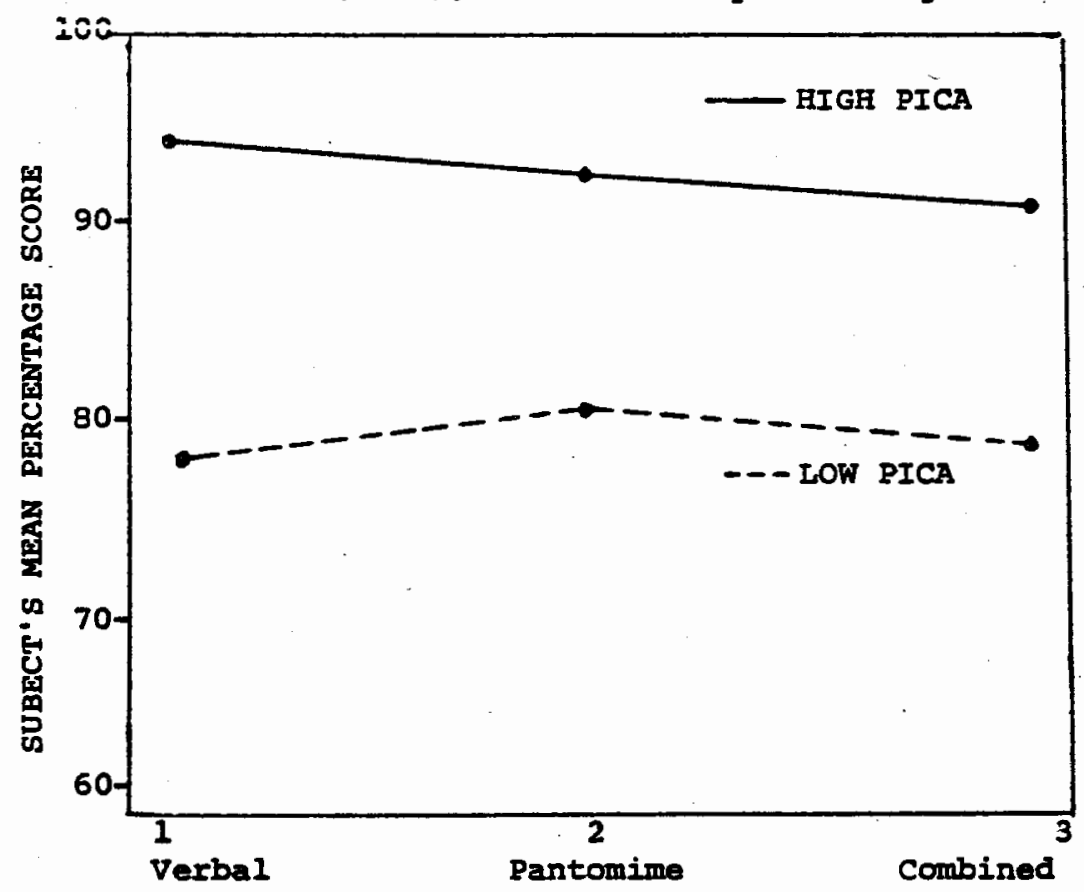

Fiqure 2. Group means for subjects with high PICA overall scores $(N=6)$ and subjects with low PICA overall scores $(N=6)$ for the three stimulus input modality groups. 


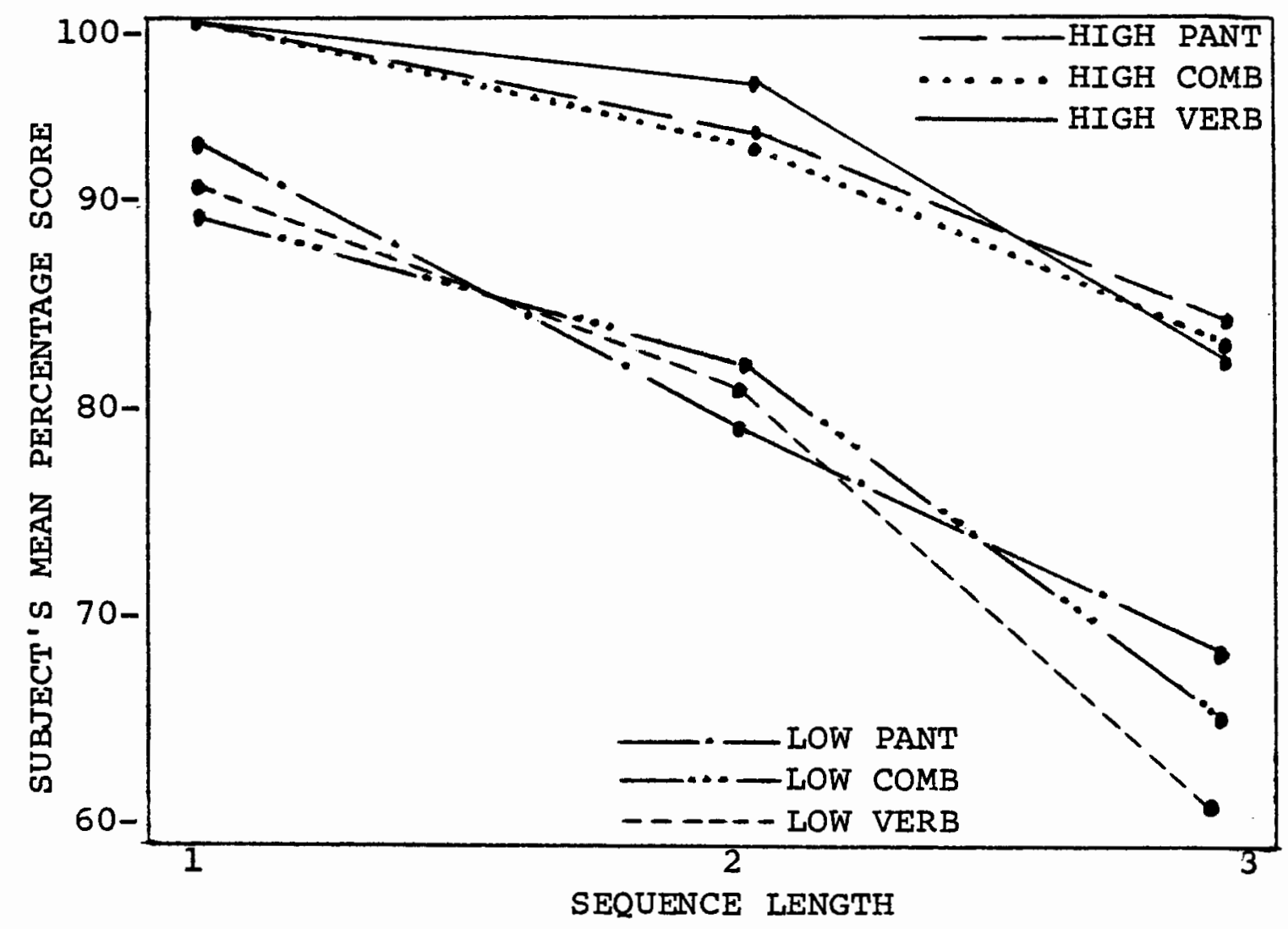

Figure 3. Group means for subjects with high PICA overall scores in each of three stimulus input modality groups (Verbal, Pantomime, Combined; $N=6$ ), and group means for subjects with low PICA scores in each of three stimulus input modality groups $(N=6)$, for three sequence lengths.

impaired across all modalities. The data did not support Duffy's finding (1975) that the auditory-verbal mode was consistently utilized more optimally than the gesturalpantomime mode.

The overall PICA scores, which, for this investigation, had been grouped into high PICA scores (above 65) and low PICA scores ( 65 and below) were shown to have a signi- 
ficant effect $(F=9.45 ; d f=1,30 ; p<.001)$ on aphasic subject's performance. Figures 1,2 and 3 illustrate high PICA groups (Verbal, Pantomime and Combined) obtained significantly better mean percentage scores on all three sequence tasks than the low PICA groups. This finding lends support to Pickett's data (1972) which showed aphasic's ability to use verbal and gestural information was related to overall severity of aphasia, reflected in the PICA score.

The findings of this investigation also indicate that sequence length adversely affects the performance of aphasics. Figures 1 and 3 show as sequence length increased from one to three stimuli, performance (mean percentage score) decreased significantly for all aphasic groups ( $F=$ 39.9; $d f=2.60 ; p<.001)$. This data supports Brown (1973), Luria (1966, 1967) and Schuell, et al. (1965) and their contention that aphasics are impaired in their ability to retain and recall word sequences.

As a further check to insure subjects in the three input modality groups could be compared, and all groups were of equal severity of aphasia, a Two-Way Analysis of Variance (Winer, 1962) of subjects' PICA scores and performance was conducted. The overall PICA scores of subjects in each input modality group were not significantly differ- 
ent $(F=.2449 ; d f=2,30)$ and, therefore, intergroup comparisons were possible. As was reported earlier, the differential interaction between high-low PICA and presentation mode was not significant $(F=1.8948 ; d f=2,30)$, but the high and low overall PICA score groups were significantly different $(F=72.83 ; d f=1,30 ; p<.001)$ (see Tables $I V$ and $V$ ).

\section{DISCUSSION}

The primary purpose of this investigation was to determine whether there was a difference in aphasic subjects' ability to utilize either verbal, pantomime, or combined stimulus inputs on a sequential recall task. The results indicated there were no significant differences between the effects of the three stimulus inputs on aphasic's recall performance. Due to the nature of the task, two interpretations of the data are possible. The first interpretation is that the input mode effect with this test instrument was smaller than the effects of the PICA score and sequence length, i.e., an input effect may exist but has been overshadowed by the strength of the other two variables. In this case, the discriminative ability of the test instrument can be questioned. As can be seen in Appendix B, the tasks did not differentiate between subject's performance 
TABLE IV

SUBJECT'S PICA SCORES

\begin{tabular}{|c|c|c|c|c|c|c|c|c|}
\hline Group & subtect & PICA & ores & & & & $\bar{x}$ & $\overrightarrow{\mathbf{x}}$ \\
\hline 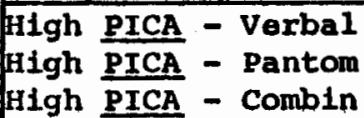 & $\begin{array}{l}97.000 \\
78.000 \\
94.000\end{array}$ & $\begin{array}{l}72.000 \\
73.000 \\
80.000\end{array}$ & $\begin{array}{l}84.0(10 \\
78.0610 \\
96.0(10\end{array}$ & $\begin{array}{l}70.000 \\
80.000 \\
77.000\end{array}$ & $\begin{array}{l}79.000 \\
79.000 \\
92.000\end{array}$ & $\begin{array}{l}98.000 \\
82.000 \\
67.000\end{array}$ & $\begin{array}{l}83.3 \\
78.3 \\
84.3\end{array}$ & 82.0 \\
\hline $\begin{array}{l}\text { Low } \frac{\text { PICA }}{\text { IICA }} \text { - Perbal } \\
\text { Low } \frac{\text { PICom }}{\text { PICA }- \text { Combin }} \\
\text { Low }\end{array}$ & $\begin{array}{l}59.000 \\
53.000 \\
54.000\end{array}$ & $\begin{array}{l}47.000 \\
65.000 \\
20.000\end{array}$ & $\begin{array}{l}43.000 \\
62.000 \\
60.000\end{array}$ & $\begin{array}{l}64.000 \\
55.000 \\
51.000\end{array}$ & $\begin{array}{l}37.000 \\
54.000 \\
50.000\end{array}$ & $\begin{array}{l}22.000 \\
51.000 \\
55.000\end{array}$ & $\begin{array}{l}45.3 \\
56.7 \\
48.3\end{array}$ & 50.1 \\
\hline
\end{tabular}

TARLE V

ANALYSIS OF VARIANCE OF SUBJECTS AND SUBJECT GROUPS

\begin{tabular}{|c|c|c|c|c|c|}
\hline Source & df & Sume of Squares & Mean Square & $\boldsymbol{F}$ & $\mathbf{P}$ \\
\hline $\begin{array}{l}\text { High-Low PICA } \\
\text { Input Mode } \\
\text { Interaction } \\
\text { Error }\end{array}$ & $\begin{array}{r}1 \\
2 \\
2 \\
30\end{array}$ & $\begin{array}{c}9152.111 \\
61.555 \\
476.22 \\
3770\end{array}$ & $\begin{array}{r}9152.111 \\
30.778 \\
238.111 \\
125.667\end{array}$ & $\begin{array}{r}72.83 \\
.2449 \\
1.8948 \\
\end{array}$ & $\begin{array}{l}<.001 \\
>.2 \\
>.1 \\
.-1\end{array}$ \\
\hline Error & $\begin{array}{l}30 \\
35\end{array}$ & $\begin{array}{l}3770 \\
13459.889\end{array}$ & 125.667 & $-\infty-\infty$ & $-\infty$ \\
\hline
\end{tabular}


(subjects scored all correct or 40 points) on: any of the three groups with high PICA subjects $(N=18)$ on the sequence length of one; two-thirds of the high PICA subjects with sequence length of two; and one-third of the high PICA, three length tasks. The task was more difficult, hence, more discriminative of the low PICA subjects: performances than high PICA performances. The instrument did not differentiate between: two-thirds of the low PICA subjects on the one word sequence length; one-third of the low PICA subjects on the two word sequence length; and one-ninth of the subjects on the three word sequence length. Figure 3 graphically illustrates that the low PICA, three sequence length task discriminates between input groups better than other tasks. However, perusing the raw scores in Appendix B, it is apparent if the scores of the very low subject in the verbal group were deleted and likewise the lowest scoring subject in the combined group, the scores of the three low PICA input groups would be similar. Three implications, therefore, can be drawn for the first interpretation: 1) the task was not difficult enough for most subjects, especially the high PICA subjects, to adequately allow group discriminations to be made; 2) the number of subjects should be greater in each group to avoid distortion 
of group means by low scorers; and 3) further investigation might be most appropriate with low PICA subjects on a three item or longer sequence task.

A factor contributing to the lack of task discrimination may have been subject's familiarity with the object array. The eight objects were not changed for the entire thirty presentations, which may have lead to some familiarity with the objects, and less challenging task at the end. Conceivably, this effect could have been controlled had the array been changed before each presentation, or had more objects been used interchangeably throughout the test. Also, to avoid any practice during the sequence presentation, the array should have been covered while presenting stimuli.

The second possible interpretation of the nonsignificant results is that no difference exists in the effects of the three input modalities; i.e.. all modalities are affected to approximately the same degree in aphasia with high and low PICA score aphasics responding similarily to complex tasks but with low $\underline{\text { PICA }}$ aphasics scoring proportionately below high PICA subjects. This is graphically illustrated in Figure 3. If this interpretation is accepted, the theory of a central processing system for language material, that 
becomes impaired with aphasia, seems to be supported. Before going on, it should be noted that although no significant interaction was found between PICA performance and sequence length, it can be seen on Figure 1 that sequence length appears to have a greater effect on low PICA subjects' performance than high PICA subjects; further investigation of this interaction might be warranted before concluding that the score proportions between high and low PICA aphasics will be the same.

An effect not controlled for in this investigation or others like it, is the effect of learning on a person's use of verbal or pantomime stimuli in recalling sequential language material. In normal persons, the auditory-verbal modality seems to be the preferred channel for language learning. It was noted by the experimenter that over half of the aphasic subjects in all groups, even the pantomime instruction group, verbally named the items as they pointed to them, though they had been instructed only to point. Perhaps learning is partially responsible for the aphasic person's greater use of verbal language than pantomime language. The multi-dimensional scoring system used in this investigation warrants discussion. This system was used to more adequately record different behavioral responses 
than a plus-minus system would have allowed. There were some drawbacks to the use of multi-dimensional scoring in this study. The scoring system was made less effective by the lack of difficulty of the task. The lack of task difficulty was reflected in the ratio of 4 , or correct, scores to all other scores, which was approximately $4: 1$. It was difficult, therefore, to generalize about scoring patterns when the preponderance of scores was in the highest category. The scoring system did allow better observation of certain behavioral patterns within input-modality groups. The 0-4 score responses of subjects were graphed (see Figures 4 and 5) and subjects in different input modality groups were shown to obtain different kinds of profiles. Subjects in the high PICA-Verbal Input group obtained more scores of 2 than the other groups. The 2 score was an indicator of the proactive inhibition or the remembering of the first items in a sequence and not the last. The low PICA-Verbal Input group also showed a trend to obtain more scores of 2 than other groups. Perhaps inherent in the auditory information channels is this ability to remember the first part of a sequence (Law of Primacy) or perhaps learning is responsible for this use of auditory information in memory. It is noteworthy that this observation is in 


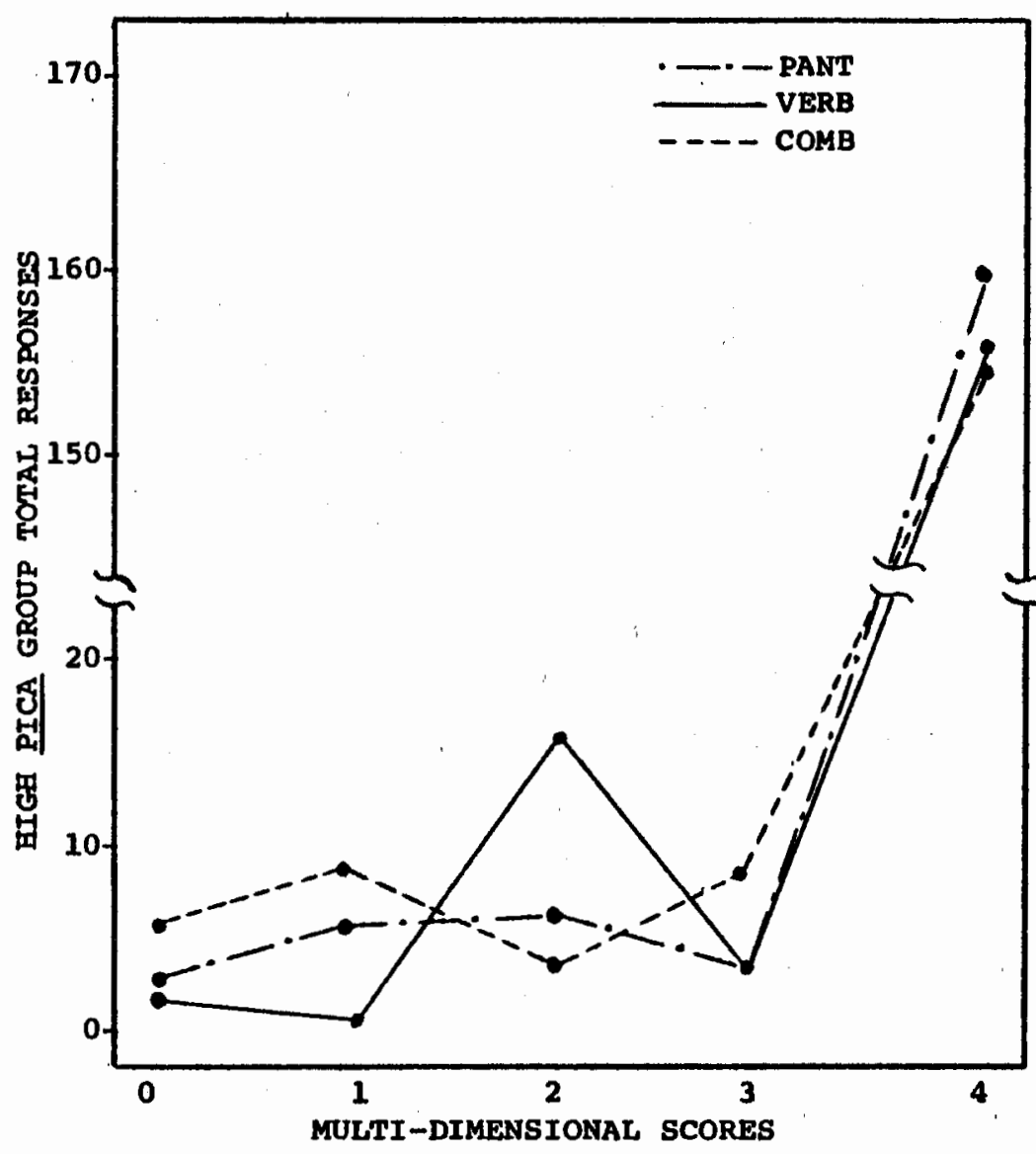

Fiqure 4. Multi-dimensional scoring pattern for the high PICA input modality groups $(N=6)$.

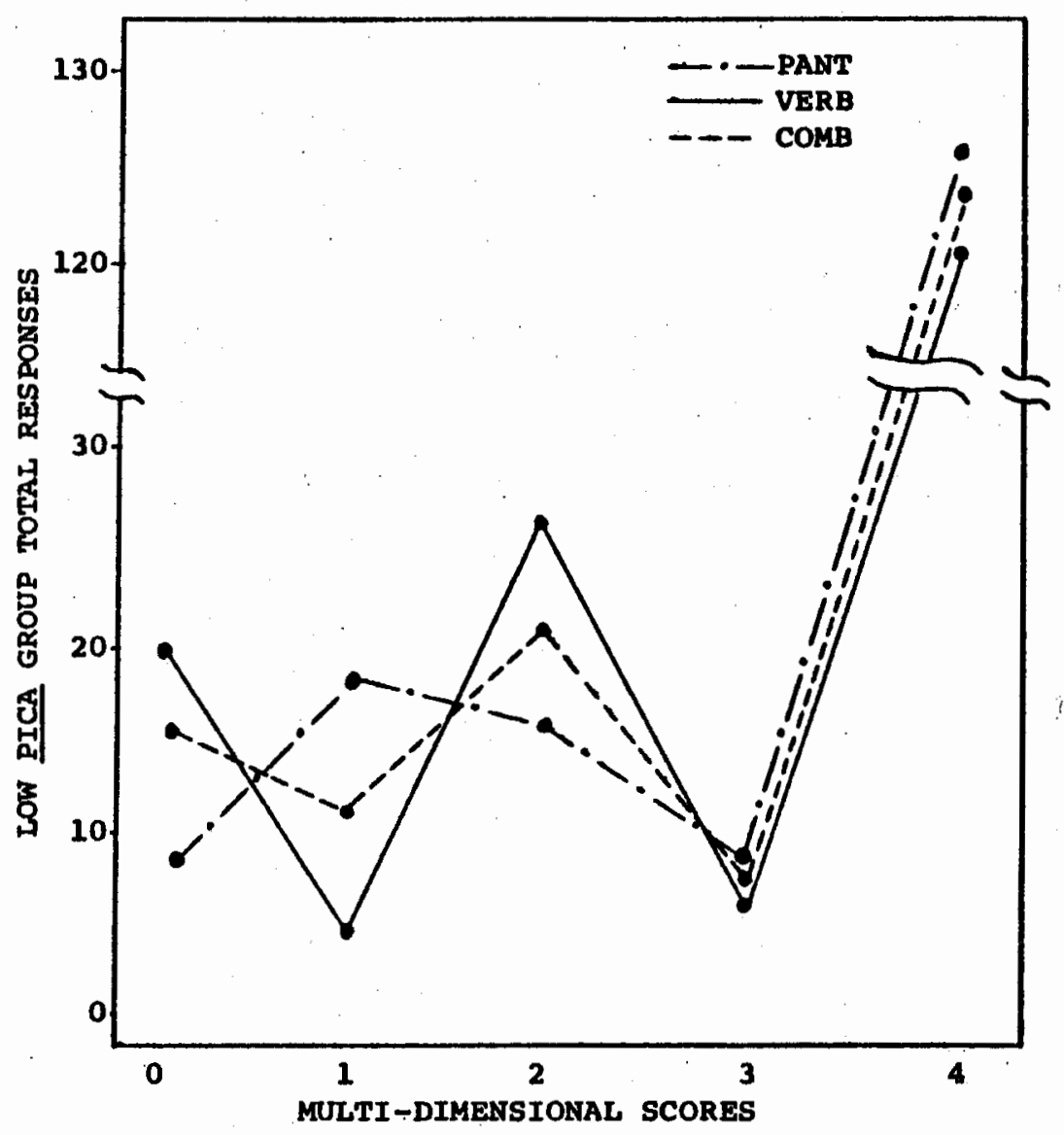

Fiqure 5. Multi-dimensional scoring pattern for the low PICA input modality groups $(N=6)$. 
opposition to Luria's (1966) observation that aphasics recall the last part of a verbal stimulus; this also differs from the observation that normals tend to recall the last part of a sequence (Penny, 1975).

The low PICA-Pantomime Input group obtained fewer 0 scores than other groups, indicating fewer repetition, incorrect, and no response behaviors. The low PICA-Pantomime Input group also scored more 1 responses than other groups, indicating a trend for retroactive inhibition, or the remembering of only the last items in a sequence (Law of Recency). Speculatively, the visual-pantomime information channel is more effective in recalling the last part of a series.

With these scoring trends in mind, it may have been predictable that the low PICA-Combined Input group scores would tend to fall somewhere between the Verbal and Pantomime group scores, and this was the case; however, a trend was noted for more 2 and 0 scores, resembling the Verbal group pattern. Although it seemed interesting to analyze the scoring profile differences between groups, it became apparent that the large amount of 4 (100\% correct) scores hampered statistical analysis and interpretation of the findings. 
The lack of discrimination and the fact that the task proved difficult only for the severe aphasic subjects, led the investigator to draw two conclusions about the use of multi-dimensional scoring in this investigation: 1) perhaps this task did not warrant the use of the multi-dimensional scoring system, or 2) the system should have been expanded to better discriminate and describe the higher response scores. At one point the experimenter did convert the multi-dimensional scores to plus-minus scores and noted there was no substantial difference between group means for either scoring system. 


\section{CHAPTER V \\ CONCLUSIONS AND IMPLICATIONS \\ I. SUMMARY AND CONCLUSIONS}

The question posed in this investigation was: Which stimulus input mode, verbal, pantomime or combined verbal and pantomime, is more effective in facilitating short term sequential recall of language material with aphasic adults?

To answer this question, thirty-six aphasic subjects were randomly divided into three groups of twelve subjects per group, six with high overall PICA scores and six with low overall PICA scores. Each subject in the three groups performed a total of thirty recall tasks which included ten tasks of one, two and three items, respectively. The experimental task presented to the first group consisted of thirty verbal sequences of words. The second group was given thirty simple pantomime sequences, and the third group's task consisted of thirty combined verbal and simple pantomime sequences.

A mixed design Three Factor Analysis of Variance (2 $\mathrm{x}$ 
$3 \times 3$ ) was utilized to statistically determine the main effects and interactions of 1 ) the input modality used in presentation of stimuli (verbal, simple pantomime, or combined), 2) the high or low overall PICA scores for subjects, 3) the sequence length of the recall task (one, two or three items) on aphasic subject's sequential recall performance.

All interactions between variables were determined to be nonsignificant, thereby making it possible to look directly at the main effects. Subjects with high and low

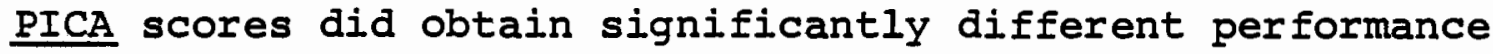
scores, with the low PICA subject groups scoring proportionately lower than high PICA groups on all sequential tasks. The present study, therefore, supported Pickett's data (1972) which showed that aphasic's ability to use verbal and gestural information was related to overall severity of aphasia, as reflected by overall PICA scores.

Results also indicated that as sequence length increased from one to three stimuli, aphasics' performance decreased significantly. The findings also support earlier work of Brown (1973), Luria (1966, 1967), and Schuell, et al. (1965), and their contention that sequence length adversely affects the performance of aphasics.

Neither the verbal, pantomime nor combined input modes 
used in the presentation of stimuli, had a significantly different effect on aphasic subject's sequential recall performance. Therefore, the primary question posed in this investigation can be answered: There does not appear to be a significantly different effect between the verbal, pantomime, and combined input modes, when they are used for instructing aphasic subjects in a sequential recall task. These findings would seem to support the theory that a central processing system for language material exists which becomes impaired across all modalities in persons with aphasia.

\section{CIINICAL IMPLICATIONS}

Two implications from this investigation might be worthy of clinical regard. First, subjects which appeared to profit most from gestural instruction were the more severe aphasic subjects engaged in a complex task. Perhaps this would be the most interesting group to observe clinically; however, it must be noted that Duffy, et al. (1975). and skelly, et al. (1974) cautioned that the gestural mode may not substantially facilitate language in aphasic or apraxic persons.

Secondly, as stimulators of language, speech pathol- 
ogists may find it feasible to stimulate across modalities to produce the broadest and greatest return of language abilities in aphasics. These findings, therefore, suggest that pantomime instruction may be useful as a more broad facilitator of language, equally useful in the recall of language materials as oral instruction.

\section{IMPLICATIONS FOR FURTHER RESEARCH}

If this investigation were to be replicated, or if further research in this area were to be explored, the following suggestions might aid the researcher: 1) The task should be made more difficult; hence, more sensitive to differences, by increasing the sequence length, incorporating more difficult gestures, and changing the item array before each presentation. Increasing the sequence length would also allow for more investigation of the relationship between PICA score and sequence length. 2) The sample size should be increased in order to avoid the distorting effect of low scorers, and to better determine the input effect, if any, on certain groups, especially the low PICA three sequence length group which showed the greatest range between input modality groups. 3) The scoring system should be changed either to a plus-minus system or to an expanded 
multi-dimensional scoring system.

If this study were to be expanded upon, it may stimulate others to study the effects of different input modalities on the proactive and retroactive inhibition patterns of recall in aphasic persons. Also, the use of this type of task set with aphasic children might lead to interesting information about the role of learning in the use of different language modalities. 
SOURCES OF REFERENCE

ALAJOUANINE, T., Lhermitte, F., Non-Verbal Communication in Aphasia. In DeReuck, A. and O'Conner, M., Disorders of Language. Boston, Massachusetts: Little, Brown and Co. (1964).

BADDELEY, A. D., Retrieval Rules and Semantic coding in Short Term Memory. Psych. Bull., 78:379-385 (1972).

BROOKSFIRE, R. H., An Introduction to Aphasia. Minneapolis, Minesota: Robert Brookshire (1973).

BROWN, I., Effects of Semantic Associational Strength and Verbal Sequence Length on the Auditory Comprehension of Aphasic Adults. Master's Thesis, Portland State University (1973).

BUCK, M., Dysphasia: Professional Guidance for Family and Patient. Englewood Cliffs, New Jersey: PrenticeHall, Inc. (1968).

CRITCHLEY, M., Aphasiology and Other Aspects of Language. London: Edward Arnold Ltd. (1970).

DUFFY, R., Duffy, J.., and Pearson, K., Pantomime Recognition in Aphasics. Journal of Speech and Hearing Research, 18:115-132 (March, 1975).

EAGLESON, H., Vaughn, G., Knudson, A., Hand Signals for Dysphasia. Arch. Phys. Med. and Rehab., 48:410-414 (1967).

EISENSON, J.. Adult Aphasia: Assessment and Treatment. New York: Appleton-Century-Crofts, Inc. (1973).

EKMAN, P., Friesen, W.., Hand Movements. J. of Comm., $2: 353-374$ (1972). 
FILBY, Y.., Edwards, A., Seacat, G., Word Length, Frequency and Similarity in the Discrimination Behavior of Aphasics. Journal of Speech and Hearing Research, $6: 255-264$ (1963).

FORDYCE, W. F., Jones, R. H., The Efficacy of oral and Pantomime Instructions for Hemiplegic Patients. Archives of Phys. Med. and Rehab., 47:676-680 (1966).

GOODGLASS, H., Denes, G., Calderon, M., The Absence of Covert Verbal Mediation in Aphasia. Cortex, 10:264269 (1974).

GOODGLASS, H. and Kaplan, E., Disturbance of Gesture and Pantomime in Aphasia, Brain. 86:703-720 (1963).

LURIA, A. R., Higher Cortical Functions in Man. New York: Basic Books, Inc. (1966).

LURIA, A. R., Sokolov, E. N., Klimkowski, M., Towards a Neurodynamic Analysis of Memory Disturbances with Lesions of the Left Temporal Lobe. Neuropsychologia, $5: 1-11$ (1967).

MILLER, G., Information and Memory. Scientific American Reprint \#419, San Francisco: W. H. Freeman and Co. (August, 1956a).

MILLER, G. A., The Magical Number Seven Plus or Minus Two: Some Limitations on our Capacity for Processing Information. Psych. Review, 63:81-97 (1956b).

PENNY, C., Modality Effects in Short Term Memory. Psych. Bull., 82:68-84 (1975).

PICK, A., Aphasia. Springfield, Illinois: Charles C. Thomas Pub. (1973).

PICKETT, L., An Assessment of Gestural and Pantomimic Deficit in Aphasic Patients. Master's Thesis, University of New Mexico (1972).

PORCH, B., Porch Index of Communicative Ability. Palo Alto, California: Consulting Psychologists Press (1967). 
PREMACK, D., Language in Chimpanzees, Children and Aphasics. Paper presented to the Academy of Aphasia, Victoria, B.C. (1975).

SARNO, J., Swisher, I., Sarno, M., Aphasia in a Congenitally Deaf Man. In Sarno, M., Aphasia: Selected Readings. New York: Appleton-Century-Crofts (1972).

SCHUELL, H., Jenkins, J., and Jimenez-Pabon, E., Aphasia in Adults: Diagnosis, Prognosis and Treatment. New York and London: Hoeber Medical Division, Harper and Row, Pub. (1965).

SKELLY, M., Schrinsky, L., Smith, R., Fust, R., American Indian Sign (Amerind) as a Facilitator of Verbalization for the Oral Verbal Apraxic. Journal of Speech and Hearing Disorders, 39:445-456 (1974).

SPERLING, G.. A Model for Visual Memory Tasks. Human Factors, 5:19-31 (1963).

STERNBERG, S., High Speed Scanning in Human Memory. Science, 153:652-654 (1966).

SWINNEY, D., and Taylor, O., Short Term Memory Recognition Search in Aphasics. Journal of Speech and Hearing Research, 14:578-588 (1971).

WICKELGREN, W. A., Acoustic Similarity Retroactive Interference in STM. Journal of Verbal Learning and Verbal Behavior, 4:53-61 (1965).

WINER, B. J., Statistical Principles in Experimental Design. New York: McGraw-Hill (1962). 
APPENDIX A

SUBJECT INFORMATION

\begin{tabular}{|c|c|c|c|c|c|c|}
\hline SUBJECT & GROUP & $\begin{array}{l}\text { CHRONOLOG- } \\
\text { ICAL AGE }\end{array}$ & $\begin{array}{l}\text { YEARS } \\
\text { POST } \\
\text { ONSET }\end{array}$ & $\underline{\mathrm{PICA}}$ & SEX & $\begin{array}{l}\text { TOTAL } \\
\text { PERFORM- } \\
\text { ANCE } \\
\text { SCORE }\end{array}$ \\
\hline 1 & 1 & 44 & 5.11 & 97 & $F$ & 118 \\
\hline 2 & 1 & 46 & 5.3 & 72 & $\mathbf{M}$ & 103 \\
\hline 3 & 1 & 50 & .9 & 84 & $\mathbf{M}$ & 114 \\
\hline 4 & 1 & 54 & 2.7 & 70 & $M$ & 100 \\
\hline 5 & 1 & 61 & .8 & 79 & $\mathbf{M}$ & 118 \\
\hline 6 & 1 & 75 & .6 & 98 & $F$ & 120 \\
\hline 7 & 2 & 49 & 4.5 & 78 & $\mathbf{M}$ & 109 \\
\hline 8 & 2 & 66 & 1.1 & 73 & $\mathbf{M}$ & 110 \\
\hline 9 & 2 & 55 & 8.0 & 78 & $\mathrm{~F}$ & 102 \\
\hline 10 & 2 & 50 & .9 & 80 & $F$ & 120 \\
\hline 11 & 2 & 54 & 6.0 & 79 & $M$ & 120 \\
\hline 12 & 2 & 61 & 1.3 & 82 & $\mathbf{M}$ & 111 \\
\hline 13 & 3 & 27 & 4.0 & 94 & $\mathbf{M}$ & 101 \\
\hline 14 & 3 & 89 & 1.0 & 80 & $\mathbf{F}$ & 107 \\
\hline 15 & 3 & 58 & 1.4 & 96 & $\mathbf{M}$ & 119 \\
\hline
\end{tabular}


YEARS

CHRONOLOG- POST

$\underline{\text { SUBJECT }}$ GROUP ICAL AGE $\underline{\text { ONSET }}$ PICA SEX

16

17

18

19

20

21

22

23

24

25

26

27

28

29

30

31

32

33

34

35

36

\section{3}

3

3

1

1

1

1

1

1

2

2

2

2

2

2

3

3

3

3

3

3
69

75

61

62

56

49

57

60

43

58

55

60

51

60

56

63

59

45

57

56

77
12.0

1.0

6.0

.7

7.9

11.0

3.5

7.7

.4

4.7

2.2

1.0

3.10

.10

16.0

1.2

2.4

1.9

5.6

1.3

2.2
77

92

67

59

47 M

43

64

37

22

53

65

62

55

54

54

51

54

20

60

51

50

50

55
TOTAL PERFORMANCE

SCORE

120

120

101

120

105

104

102

59

73

75

102

91

120

106

90

112

57

116

113

94

81 


\section{APPENDIX B}

HIGH PICA SUBJECT'S RAW SCORES

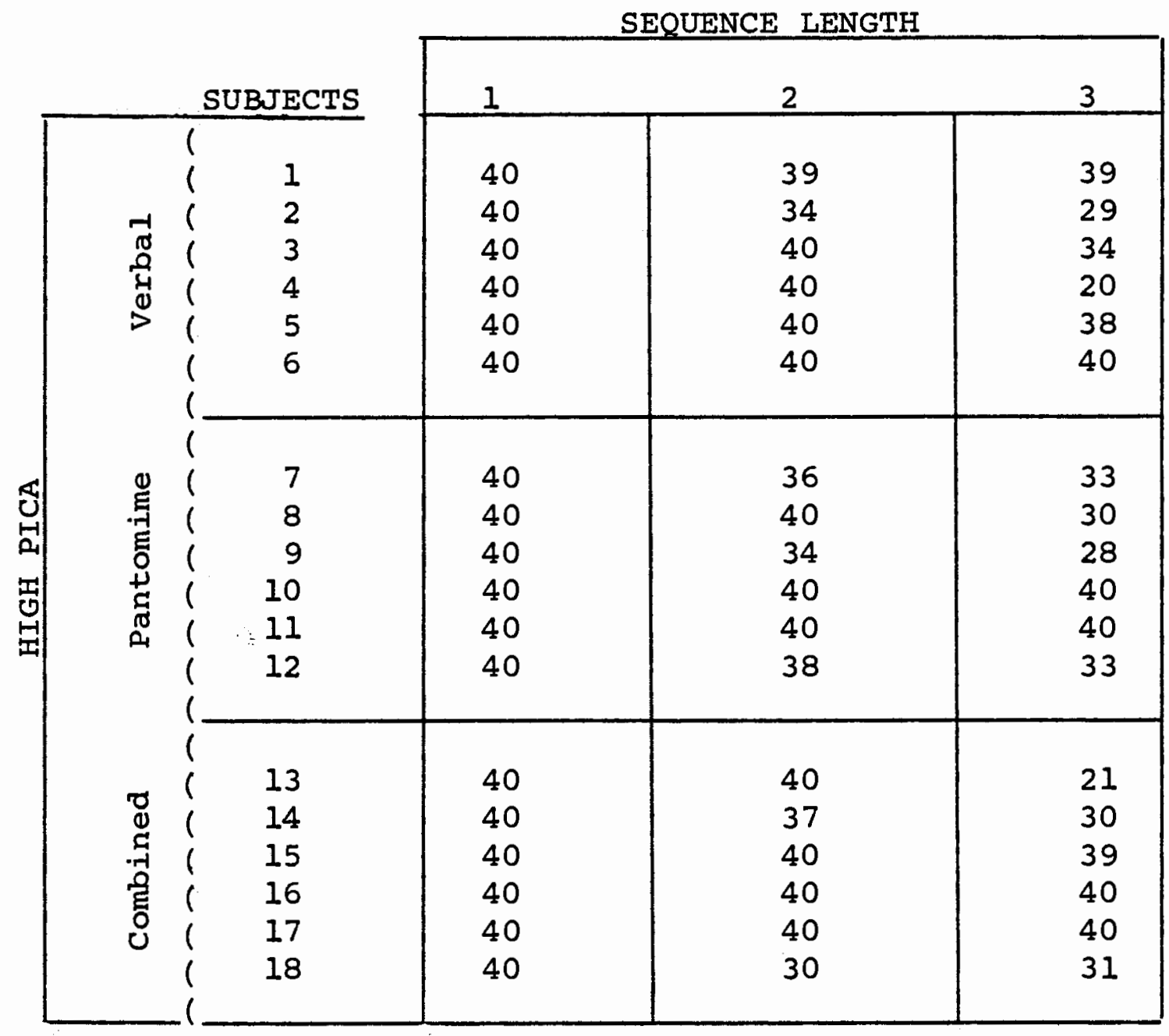


LOW PICA SUBJECT'S RAW SCORES

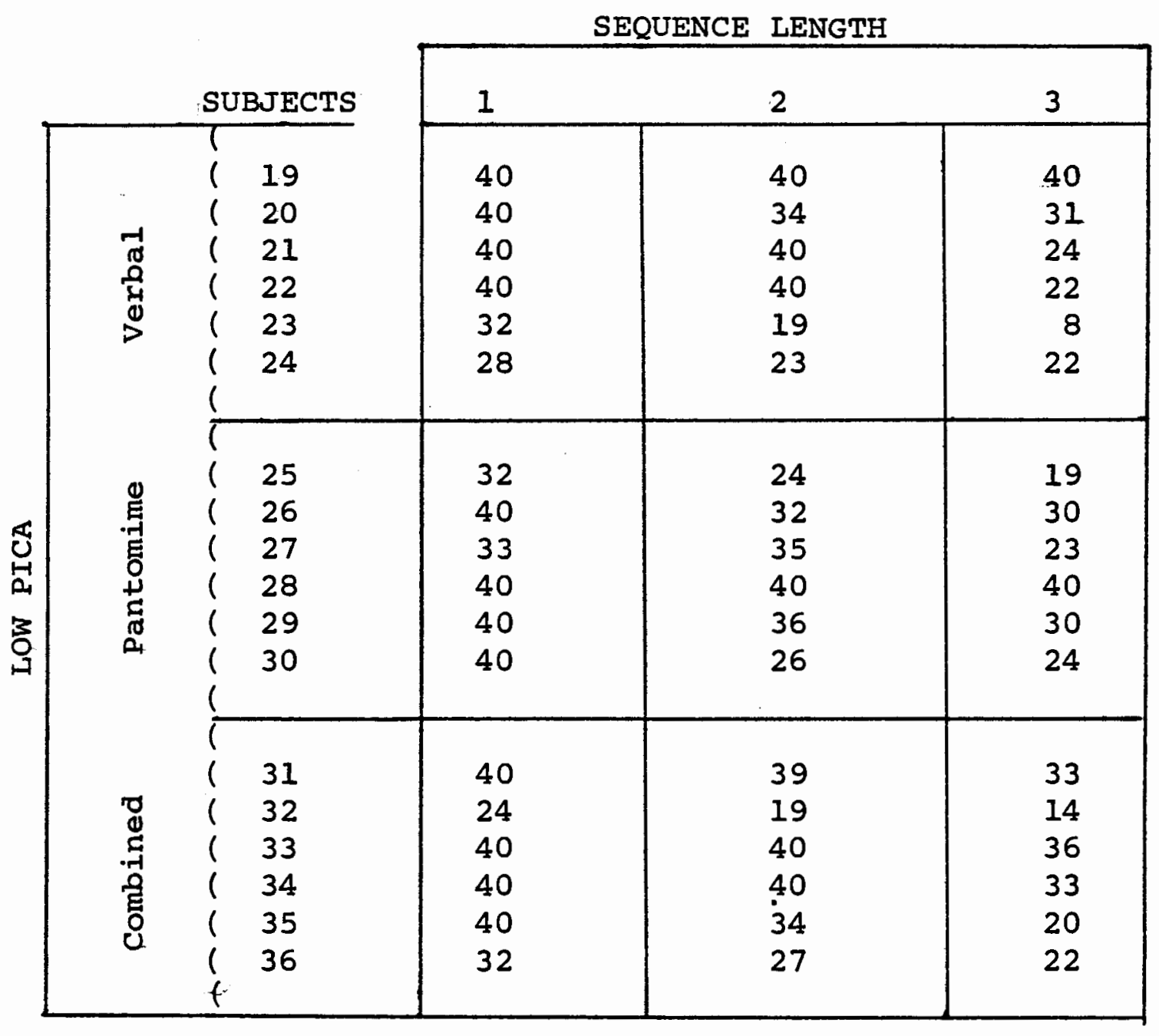

